\title{
Educational program for Psychiatric nurses to improve their knowledge and attitude toward application of evidenced based nursing practices
}

Nahed Ahmed Morsy: Prof. of Psychiatric and Mental Health Nursing, Faculty of Nursing, Tanta University

Mervat Hosny Shalaby: Assistant Prof. of Psychiatric and Mental Health Nursing, Faculty of Nursing, Tanta University

Sabah Abo Elftoh Mohamad :Lecturer of Psychiatric and Mental Health Nursing Faculty of Nursing, Kafr ElSheikh University

\begin{abstract}
Background: Evidence-based practice (EBP) is defined as the conscientious, explicit, and judicious use of current best evidence to provide services for clients in addition to integration of the best available research findings, patient preference with clinical expertise to enhance decision making. EBP helps the psychiatric nurses keep up to date with the best, clinically relevant research in the field and increases confidence in decision. EBP weighs risk, benefit, and cost against a backdrop of patient preferences.
\end{abstract} Aim: the Study aimed to evaluate the effect of an educational program about concept of Evidence-Based Nursing Practice on psychiatric nurses' knowledge and attitude. Design: This study followed is a quasi-experimental design. Setting: it was conducted at Tanta Mental Health Hospital affiliated to the ministry of health and population. Subjects: The subjects of this study were 60 nurses. Tools: two tools were used (1) Evidence Based Practice Questionnaire (EBPQ), and (2) Evidence-based Practice Attitude Scale (EBPAS). Results: the main results revealed that the attitude of the studied nurses about EBP was improved after program implementation. Statistically significant positive relationship was found between total level of knowledge and attitude among the studied nurses regarding evidence based practice. Conclusion: The present study concluded that evidence based practice is greatly important for nurse and patient and overall nursing profession. Recommendations: the present study 
recommended that continuous In-service training programs are needed to be implemented for nurses to provide the necessary skills for application of EBP in clinical practice area.

Key words: evidence based practice, psychiatric, nurses, educational program. 


\section{Introduction}

Evidence-based practice became the standard of care in psychiatric nursing and mental health care. In mental health, the most relevant evidence is ideally from research or evidence-based theories, but other evidence such as expert opinion, patient data, and clinical experiences are also used. So, competent nurses are expected to make decisions based on research findings, monitor and document the effects of interventions, and use concrete, observable, and measurable terms and instruments to demonstrate outcomes (1).

Evidence based practice is a holistic approach to care delivery that places the individual patient at its core. It is far more than research utilization alone and is a partnership between inter professional clinicians, patients and the best available evidence to optimize patient outcomes. Component EBP includes the clinical state and the clinical setting ${ }^{(2)}$. This area also requires that the provider individualizes the understanding of the patient's illness experience to include the unique aspects of symptoms, personal life concerns and situations. These economic, environmental, and social circumstances are devoted from culture. EBP positions nurses to have a significant influence on health-care decisions and be a partner in improving quality of care $^{(3)}$.

Evidence based practice has been defined as "the integration of the best possible research to evidence with clinical expertise and with patient needs" and "the conscientious, explicit, and judicious use of the best evidence from systematic research to make decisions about the care of individual patients. In order for EBP to truly work and to impact upon today's health delivery systems, it must arise from the practice setting and include the actual practitioners involved in care delivery ${ }^{(4,5)}$.

Beyond an expectation for professional practice, EBP provides a major opportunity for nurses to enlighten practice and add value to the patient's experience. Today, nursing interventions and processes informed by the best evidence are critical to realizing health-care improvements and cost savings. In light of the fact that evidence based practice has been demonstrated to yield significantly improved patient outcomes, it is indeed very worrying to know that it is not yet widely utilized in psychiatric nursing ${ }^{(6)}$. 
Evidence suggests that clinicians tend to underestimate their information requirements and, when they do recognize a need for information, they do not access the most reliable and least biased sources. This leads to a gap between research and clinical practice which manifests as unwarranted variations in clinical practice. There are only two explanations for these variations: either there is no evidence on which to base practice, or that there is evidence, but at least some of us are not using it. The inevitable result of these variations is that some patients are not receiving the best available care ${ }^{(7)}$.

Many psychiatric/mental health nursing (PMHN) practices have been affected by old traditions and haphazard trial and error instead of established scientific evidence. Barriers surrounding evidence-based practice explain the lack of EBP in today's PMHN environment. These barriers include: the nature of the evidence, the contribution of the psychiatric nursing researchers to EBP, the personal characteristics of psychiatric nurses, and organizational factors. While the challenge, is to build up creative strategies through which psychiatric nurses are better able to provide EBP care as part of their everyday performance ${ }^{(8-10)}$.

Adaptation of a more dynamic form of EBP, increasing the number of PMHN researchers, conducting clinical research projects, choosing suitable journals for publication, training the psychiatric nurses about computer skills, integrating the EBP principles into nursing curricula, developing journal clubs, and offering organizational facilitators are essential prerequisites for the achievement of EBP in the PMHN field. It is no longer justifiable for psychiatric nurses to be deficient in knowledge and skill since the advantages of EBP for patients are well-documented ${ }^{(8)}$.

The process of developing evidence-based nursing practice begins with a question about a specific patient problem or situation. Systematic search for evidence that could be used to answer the question follows. Once the evidence is obtained, its validity, relevance, and applicability are appraised. The evidence is then integrated with other information including; nurses' experience, patient preferences for alternative forms of care, and available resources. Taken together, these factors influence management of the clinical problem. Finally, the evidence-based practice decision is implemented and the outcome of the decision is evaluated and disseminated ${ }^{(11,12)}$.

Determining the relevance of the evidence requires three critical thinking skills that are increasingly being recognized as the cognitive engine driving the process of knowledge development and use: analysis, evaluation, and interpretations. Analysis 
involves examining the evidence and its component parts and reducing the complexity of the evidence into simpler or more basic components or elements. The focus of the analysis should be determining the degree of alignment among the practices in question, the evidence indicators, and the evidence-gathering strategy used. Evaluation involves determining the precision, accuracy, and integrity of the evidence through careful appraisal of the results of the evidence-gathering strategy ${ }^{(13)}$.

As the psychiatric and mental health nursing specialty moves to embrace evidencebased practice, there is work to be done in three areas: personnel, process, and product. There is a need for more researchers who possess both clinical knowledge and research expertise, and these nurse researchers need to increase the depth and scope of their research. With the current nursing shortage in all areas of nursing and the predicted shortage of nursing faculty, increasing the number of psychiatric nurse researchers is a challenge. Thus, those in practice and in academic settings must work together to encourage young men and women to become nurses and psychiatric and mental health nurses in particular ${ }^{(14,15)}$. 
The aim of this study is to evaluate the effect of an educational program about concept of Evidence-Based Nursing Practice on psychiatric nurses' knowledge and attitude.

Research question: Psychiatric nurses' knowledge and attitude about concept of evidence based nursing practice was improved after implementing the educational program.

\section{Materials \& Method}

Research design:-The design followed in this study was a quasi-experimental design.

Setting:The study was conducted at Tanta Mental Health Hospital affiliated to the Ministry of Health with a capacity of 75 beds divided into three wards for men(50 beds) and two wards for women ( 25 beds). It provides health care services to Gharbya, Menofia, and KafrElsheikh governates.

Subjects: The target population of this study was 60 nurses (all available convenient nurses from the previous setting) who fulfilled the following inclusion criteria:

- Willing to participate in the study.

- Have at least two years working experience at mental health hospitals.

- Provide direct care to psychiatric patients. 


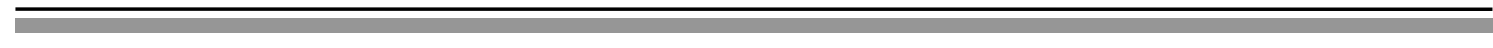

(7) 


\section{Tools of the study:}

The data of this study was collected using the following tools:

Tool I: Evidence Based Practice Questionnaire (EBPQ). It consisted of two parts

\section{Part one: Socio-demographic and work experience data:}

It was developed by the researcher to elicit the sociodemographic data about nurses as age, sex, level of education, residence, years of experience.

\section{Part two: Evidence Based Practice Questionnaire (EBPQ).}

It was developed by Kate Gerrish (2007) ${ }^{(16)}$ to assess knowledge used by nurses in their practice, barriers and facilitators of EBP. It comprised of 49 items presented in the following five sections:

- Section 1 contains 22 items that measure sources of knowledge used by nurses in their practice. Each item is scored on a 5-point Likert scale from 1 (never) to 5(always).

- Section 2 contains 10 items that measure variables related to barriers to finding and reviewing evidence. Each item is scored on a 5-point Likert scale from 1 (disagree strongly) to 5 (agree strongly).

- Section 3 contains 5 items that measure barriers to changing practice. Each item is scored on a 5-point Likert scale from 1 (disagree strongly) to 5 (agree strongly).

- Section 4 contains 4 items that measure variables related to facilitators of EBP. Each item is scored on a 5-point Likert scale from 1 (disagree strongly) to 5 (agree strongly).

- Section 5 contains 8 items that measure self-assessment of skills. Each item is scored on a 5-point Likert scale ranging from (complete beginner) to 5 (expert).

Each nurse can receive score ranging from 49 to a 245 grades.

Evaluation of this questionnaire was as follows:

$$
<50 \%=\text { Poor } \quad 50-65 \%=\text { Average } \quad>65 \% \quad=\text { Good }
$$




\section{Tool II: Evidence-based Practice Attitude Scale (EBPAS):}

Evidence-based Practice Attitude Scale was developed by Gregory Aarons (2004) $^{(17)}$. It is a 15 -item self-report scale aimed to measure attitude about using Evidence-based Practice.

Each statement was rated on a 5 point Likert scale where $0=$ not at all, $1=$ to a slight extent, $2=$ to a moderate extent, $3=$ to a great extent, $4=$ to a very great extent.

Every nurse can receive scores ranging from 0 to a 60 grades classified as

\section{follows:}

Less than median = negative attitude.

Median and more than median= positive attitude.

\section{Method}

The steps that have been followed in this study were as follow:

- An official approval was obtained from the identified hospital to collect the study data.

- Tool I part 2 Evidence Based Practice Questionnaire (EBPQ) and tool II Evidence-based Practice Attitude Scale (EBPAS) were translated into Arabic by the researcher.

- Tool I part 2 and tool II were translated to Arabic language by the researcher and tested to ascertain content validity and the required corrections by a group of 5 experts in the psychiatric field.

- A test -retest reliability was applied on the two previously mentioned tools to test the internal consistency. Test - retest reliability was 0.96022 .

- Before embarking in the actual study: A pilot study was carried out on 10 nurses after taking their approval to ascertain the clarity and applicability of the study tools. In addition, it served to identify obstacles that might be faced during data collection. These nurses were excluded from the study sample. 
- Informed consent was obtained from the studied nurses after explaining the purpose of the study and assuring the nurses about their privacy and confidentiality of the obtained data. The nurses were informed that they have a right to withdraw from the study at any time if they wanted.

- Tool I and tool II were applied two times. The first one pre-test and the second posttest immediately after application of the program and after three months.

- The selected nurses undergone a pre-test using Evidence-based Practice Attitude Scale (EBPAS) and Evidence Based Practice Questionnaire (EBPQ).

- The researcher distributed the two tools to nurses and asked them to fill them in the presence of the researcher for necessary clarification.

\section{Implementation of the program:}

- The educational program was developed by the researcher based on the results from pre-test and the review of related literature ${ }^{(1,18-24)}$.

- The educational program was divided into five sessions:

- Session 1: Introductory session, definition and importance of evidence-based practice.

- Session 2: Types and steps of evidence-based Practice.

- Session 3: Barriers and challenges of evidence-based practice.

- Session 4: Giving example about the application of evidence-based practice in nursing care plan for schizophrenia.

- Session 5: Immediate post-test by using tool I part 2 and tool II.

The study subjects were divided into subgroups, each group composed of 5-7 nurses. Each group was met, three times per week, for duration of 45 minutes each, and this for 5 sessions.

The program was presented through discussion between the researcher and the nurses, audiovisual materials and handouts were used whenever needed to supplement discussion. 
The evaluation of educational program was done at the end of $5^{\text {th }}$ session (immediate posttest) and after three months using tool I part 2 and tool II as post-test 2.

The study was conducted in April 2014 and finished in September 2014.

\section{Statistical analysis:}

The collected data was organized, tabulated, coded and statistically analyzed using the mean, standard error, unpaired student t-test, the linear correlation coefficient, Analysis of variance [ANOVA] tests Paired t-test and chi-square by SPSS V17.

\section{Limitation of the study}

- Nurses had many challenges during time of the study such as; work overload which lead to repeated out during the educational program sessions.

- The researcher was exposed to many interruptions from patients and staff members and noise from maintenance works in the hospital

- The training hall isn't equipped with the necessary tools for training.

- A self-completion questionnaire is not the best way to gather the views of individual professionals about such a complex subject, with respondents' verbal explanations of key terms were often differing from their written responses

\section{Acknowledgement:}

The researcher would like to express their sincere gratitude to the all nurses and staff of Tanta mental health hospital who helped in facilitating conduction of this study. Great appreciation as well is all researcher who shared in this research

\section{Results}

Table 1 presents Socio-demographic and work experience of the studied nurses. The results revealed that most of nurses were females (76.67\%) with a mean age of $32.333 \pm 8.206$ years. Regarding their residence, more than half of the nurses (63.33\%) lived in rural areas. Concerning the nurses' marital status, those who were married represented more than three quarters of the studied nurse $(83.33 \%)$. In relation to nurses' educational level, about half of nurses had a secondary school 
nursing diploma (46.67\%) while about one third had technical nursing institute (33.33\%). Regarding their occupation, about three quarters of the studied nurses were bedside nurses (76.67\%). Regarding nurses' work experience, most of them (70\%) had working experience more than 5 years.

Table 2 presents the distribution of the studied nurses according to total score of their level of knowledge regarding evidence based practice before, immediate and 3 months after educational program implementation. The results revealed that, $45 \%$ of the nurses have average knowledge about bases of practice knowledge (section I) before the implementation of the educational program, while $56.67 \%$ of studied nurses had good knowledge immediately after the educational program, but after three months from the implementation of the educational program $60 \%$ of them returned to average knowledge .

In relation to knowledge about barriers to finding and reviewing evidence (section II), the results revealed that about half (48.33\%) of the studied nurses had good knowledge about barriers before the educational program. While immediately after and after three months from the implementation of the educational program, $45.00 \%$ of the studied nurses had average knowledge about barriers.

Regarding knowledge about barriers to changing practice on the basis of evidence (section III), the results presented that $56.67 \%$ of the studied nurses had average knowledge about barriers before the educational program. While immediately after the educational program implementation, less than half (45.00\%) of the studied nurses had good knowledge about barriers compared by $28.33 \%$ fall in the same category after three months from implementation of the program.

In relation to knowledge about facilitation and support in changing practice (section IV), the results presented that before the educational program $63.33 \%$ of nurses had good knowledge about facilitations, while more than half (66.67\%) of the studied nurses in the same category immediately after the educational program implementation compared by $43.33 \%$ of them after three months from implementation of the program.

Finally, regarding self-assessment of skills (section V), the results revealed that before the educational program $33.33 \%$ of the studied nurses had average skills to EBP, 
while immediately after the educational program implementation $28.33 \%$ of them had average skills to EBP compared with $25.00 \%$ fall in the same category three months after the educational program implementation.

Table 3\&4 show studied nurses total attitude score regarding evidence based practice. The results showed that $36.67 \%$ of studied nurses had a positive attitude regarding evidence based practice before the educational program. While it increased to $76.67 \%$ to fall in the same category immediately after the educational program implementation compared with $46.67 \%$ of nurses fall in the same category three months after the educational program implementation.

Table 5 illustrates the correlation between total level of knowledge and attitude among the studied nurses regarding evidence based practice. The results revealed a statistically significant positive relationship between total level of knowledge and attitude among the studied nurses regarding evidence based practice where P-value $<0.001$. 
Table (1):- Distribution of the studied nurses according to their socio-demographic characteristics and work experience.

\begin{tabular}{|c|c|c|}
\hline \multirow{2}{*}{ Socio-demographic characteristics } & \multicolumn{2}{|c|}{ studied nurses $(\mathrm{N}=60)$} \\
\hline & $\mathrm{N}$ & $\%$ \\
\hline \multicolumn{3}{|l|}{ Age (years) } \\
\hline $20-$ & 26 & 43.33 \\
\hline $30-$ & 28 & 46.67 \\
\hline $40-$ & 2 & 3.33 \\
\hline $50-$ & 4 & 6.67 \\
\hline Mean \pm SD & \multicolumn{2}{|c|}{$32.333 \pm 8.206$} \\
\hline \multicolumn{3}{|l|}{ Sex } \\
\hline Female & 46 & 76.67 \\
\hline Male & 14 & 23.33 \\
\hline \multicolumn{3}{|l|}{ Residence } \\
\hline Rural & 38 & 63.33 \\
\hline Urban & 22 & 36.67 \\
\hline \multicolumn{3}{|l|}{ Marital status } \\
\hline Married & 50 & 83.33 \\
\hline Single & 7 & 11.67 \\
\hline Widow & 3 & 5.00 \\
\hline \multicolumn{3}{|l|}{ Level of education } \\
\hline Diploma & 28 & 46.67 \\
\hline Technical nursing institute & 20 & 33.33 \\
\hline Bachelor & 11 & 18.33 \\
\hline Higher studies & 1 & 1.67 \\
\hline \multicolumn{3}{|l|}{ Occupation } \\
\hline Nurse & 46 & 76.67 \\
\hline Supervisor & 14 & 23.33 \\
\hline \multicolumn{3}{|l|}{ Work experience (years) } \\
\hline$<5$ & 18 & 30.00 \\
\hline$>5$ & 42 & 70.00 \\
\hline
\end{tabular}


Table (2):- Distribution of the studied nurses according to total score of their level of knowledge regarding evidence based practice before, immediate and 3months after educational program implementation $(N=60)$

\begin{tabular}{|c|c|c|c|c|c|c|c|c|c|}
\hline \multirow{3}{*}{\multicolumn{2}{|c|}{ Level of knowledge }} & \multicolumn{8}{|c|}{ Studied nurses } \\
\hline & & \multicolumn{2}{|c|}{ Before } & \multicolumn{2}{|c|}{ Immediate } & \multicolumn{2}{|c|}{$\begin{array}{l}\text { After } 3 \\
\text { months }\end{array}$} & \multicolumn{2}{|c|}{ Chi-square } \\
\hline & & $\mathbf{N}$ & $\%$ & $\mathbf{N}$ & $\%$ & $\mathbf{N}$ & $\%$ & $X^{2}$ & P-value \\
\hline \multirow{3}{*}{$\begin{array}{l}\text { I. Bases of practice } \\
\text { knowledge }\end{array}$} & Poor & 7 & 11.67 & 3 & 5.00 & 5 & 8.33 & \multirow{3}{*}{8.972} & \multirow{3}{*}{0.062} \\
\hline & Average & 27 & 45.00 & 23 & 38.33 & 36 & 60.00 & & \\
\hline & Good & 26 & 43.33 & 34 & 56.67 & 19 & 31.67 & & \\
\hline \multirow{3}{*}{$\begin{array}{l}\text { II. Barriers to finding } \\
\text { and reviewing } \\
\text { evidence }\end{array}$} & Poor & 9 & 15.00 & 10 & 16.67 & 14 & 23.33 & \multirow{3}{*}{4.071} & \multirow{3}{*}{0.395} \\
\hline & Average & 22 & 36.67 & 27 & 45.00 & 27 & 45.00 & & \\
\hline & Good & 29 & 48.33 & 23 & 38.33 & 19 & 31.67 & & \\
\hline \multirow{3}{*}{$\begin{array}{l}\text { III. Barriers to changing } \\
\text { practice on the basis } \\
\text { of evidence }\end{array}$} & Poor & 12 & 20.00 & 9 & 15.00 & 25 & 41.67 & \multirow{3}{*}{19.386} & \multirow{3}{*}{$<0.001 *$} \\
\hline & Average & 34 & 56.67 & 24 & 40.00 & 18 & 30.00 & & \\
\hline & Good & 14 & 23.33 & 27 & 45.00 & 17 & 28.33 & & \\
\hline \multirow{3}{*}{$\begin{array}{l}\text { IV. Facilitation and } \\
\text { support in changing } \\
\text { practice }\end{array}$} & Poor & 11 & 18.33 & 7 & 11.67 & 8 & 13.33 & \multirow{3}{*}{12.268} & \multirow{3}{*}{$0.015^{*}$} \\
\hline & Average & 11 & 18.33 & 13 & 21.67 & 26 & 43.33 & & \\
\hline & Good & 38 & 63.33 & 40 & 66.67 & 26 & 43.33 & & \\
\hline \multirow{3}{*}{$\begin{array}{l}\text { V. Self-assessment of } \\
\text { skills }\end{array}$} & Poor & 35 & 58.33 & 35 & 58.33 & 32 & 53.33 & \multirow{3}{*}{4.575} & \multirow{3}{*}{0.322} \\
\hline & Average & 20 & 33.33 & 17 & 28.33 & 15 & 25.00 & & \\
\hline & Good & 5 & 8.33 & 8 & 13.33 & 13 & 21.67 & & \\
\hline
\end{tabular}


Table (3):- Distribution of the studied nurses total attitude score regarding evidence based practice before, immediate and after three months from the implementation of the educational program. $(\mathrm{N}=60)$

\begin{tabular}{|c|c|c|c|c|c|c|c|}
\hline \multirow{3}{*}{\multicolumn{2}{|c|}{ Attitude }} & \multicolumn{6}{|c|}{ Studied nurses } \\
\hline & & \multicolumn{2}{|c|}{ Pre } & \multicolumn{2}{|c|}{ Immediate } & \multicolumn{2}{|c|}{ After 3 months } \\
\hline & & $\mathbf{N}$ & $\%$ & $\mathbf{N}$ & $\%$ & $\mathbf{N}$ & $\%$ \\
\hline \multicolumn{2}{|c|}{ Negative } & 38 & 63.33 & 14 & 23.33 & 32 & 53.33 \\
\hline \multicolumn{2}{|c|}{ Positive } & 22 & 36.67 & 46 & 76.67 & 28 & 46.67 \\
\hline \multirow{2}{*}{ Chi-square } & $\mathbf{X}^{2}$ & \multicolumn{6}{|c|}{20.893} \\
\hline & P-value & \multicolumn{6}{|c|}{$<0.001 *$} \\
\hline
\end{tabular}

Table (4):- Comparison of the studied nurses attitude toward evidence based practice regarding Paired Differences before, immediately and after three months from the implementation of the educational program. $(\mathrm{N}=60)$

\begin{tabular}{|c|c|c|c|c|c|c|c|c|c|c|}
\hline \multirow{2}{*}{$\begin{array}{c}\text { Educational } \\
\text { program }\end{array}$} & \multicolumn{5}{|c|}{ Studied nurses' attitude } & \multirow{2}{*}{ Comparison } & \multicolumn{2}{|c|}{$\begin{array}{c}\text { Paired } \\
\text { Differences }\end{array}$} & \multicolumn{2}{|c|}{$\begin{array}{c}\text { Paired Samples } \\
\text { Test }\end{array}$} \\
\hline & & lange & Mear & \pm & SD & & Mean & SD & $\mathbf{T}$ & P-value \\
\hline Before & 19.00 & -53.00 & 35.9 & \pm & 7.18 & $\begin{array}{c}\text { Before - } \\
\text { Immediate }\end{array}$ & $\begin{array}{c}- \\
12.23\end{array}$ & 8.82 & $\begin{array}{c}- \\
10.74\end{array}$ & $<0.001 *$ \\
\hline Immediate & 19.00 & -60.00 & $48.1^{7}$ & \pm & 8.32 & $\begin{array}{l}\text { Before - } \\
\text { After } 3 \\
\text { months }\end{array}$ & -6.53 & 10.53 & -4.80 & $<0.001 *$ \\
\hline $\begin{array}{l}\text { After } 3 \\
\text { months }\end{array}$ & 22.00 & -59.00 & 42.4 & \pm & 8.03 & $\begin{array}{c}\text { Immediate- } \\
\text { After } 3 \\
\text { months }\end{array}$ & 5.70 & 10.69 & 4.13 & $<0.001 *$ \\
\hline
\end{tabular}


Table (5):- Correlation between total level of knowledge and attitude among the studied nurses regarding evidence based practice

\begin{tabular}{|c|c|}
\hline \multicolumn{2}{|c|}{ Correlations between Attitude and Total knowledge } \\
\hline $\mathbf{R}$ & P-value \\
\hline 0.464 & $<0.001 *$ \\
\hline
\end{tabular}

\section{Discussion}

Evidence based practice is really important to make the patient more satisfied with the psychiatric nursing care. Also, it ensures the safety for nurses, patients and organizations. EBP increases the ability of nurses to be more updated with the most recent and scientific researches and to involve the patient in the nursing process which enables her to introduce efficient and powerful nursing care.

The aim from this study was to evaluate the effect of an educational program about concept of evidence-based nursing practice on psychiatric nurses' knowledge and attitude. Regarding hypothesis of this study, psychiatric nurses' knowledge and attitude about concept of evidence based nursing will improve after the implementation of educational program, the results of this study are in accordance with this hypothesis.

Regarding total knowledge score, the present study represented improvement in the total knowledge level immediately after implementation of the educational program compared with before the implementation of the educational program. This result may be probably due to the immediate effect of educational program session which was supported by booklet about the evidence based practice. While three months after implementation of the educational program, this improvement decreased which may be probably due to absence of continuing training and education, inability to apply the evidence based practice in real clinical area, work overload which didn't allow the nurses to use EBP. 
Regarding base of knowledge (section I), the present study represented that the majority of the nurses had good level of knowledge especially in the statements of information they learn about each patient/client as an individual, their intuitions about what seems to be 'right' for the patient/client, their personal experience of caring for patients/clients over time, what has worked for them for years, the ways they have always done it, information their fellow practitioners share, information senior clinical nurses share, what doctors discuss with them, new treatments and medications that they learn when doctors describe them for patients, information from attending in-service training/conferences, information they get from local and national policy and protocols and guidelines. These results may be related to that nurses depend on experience, information transferred from one to another, limited training conferences offered by the hospital and the majority of the studied nurses aren't highly educated.

This result is in agreement with Dalheim , et al.(2012) ${ }^{(25)}$ in their study of factors influencing the development of evidence-based practice among nurses: a self-report survey that aimed to examine factors influencing the implementation of EBP among nurses in a large Norwegian university hospital, reported that nurses largely used experienced-based knowledge collected from their own observations, colleagues and other collaborators for support in practice while evidence from researches was seldom used.

Regarding knowledge of nurses about barriers to finding and reviewing evidence (section II), the present study is in agreement with the study of Dalheim, et al.(2012) ${ }^{(25)}$ that the majority of nurses face barriers. Most common barriers were that the nurses do not know how to find organizational information, they do not have sufficient time to find research reports or organizational information, research reports and organizational information is not easy to find, they do not feel confident in judging the quality of research reports, they find it difficult to identify the implications of research findings or organizational information for their own practice. This result may be probably due to majority of the studied nurses were females and have multiple duties and responsibilities beside their work, live in rural areas in which there is no sufficient facilities such as libraries or internet, hospital doesn't provide libraries, halls of the 
Internet, national or international journals their level of education didn't reach the necessary and sufficient information about scientific research or evidence based practice, insufficient training courses on how to understand and apply scientific researches and absence of continuing education plans for nurses.

In the same direction, Olade (2004) ${ }^{(26)}$ in her study of strategic collaborative model for evidence-based nursing practice aimed to describe a model that has been developed to guide nurses and other health professionals in collaborative efforts toward evidencebased nursing practice. She reported that a number of barriers to evidence-based nursing practice, have persisted over the last two decades, including inadequate knowledge of research among practicing nurses, lack of administrative support for research activities in clinical settings, lack of empowerment of nurses, and lack of needed mentoring from nursing research consultants.

Regarding this respect, Yadav \& Fealy (2012) ${ }^{(27)}$, in their study about Irish psychiatric nurses' self-reported barriers, facilitators and skills for developing evidencebased practice that aimed to examine and describe barriers, facilitators and skills for developing EBP. They reported the same barriers mentioned in the present study findings except that the Irish nurses were more confident about beginning to change the traditional practice to evidence based practice.

In relation to knowledge of nurses about barriers to changing practice on the basis of evidence (section III), the present study represents common barriers that face nurses were; lack of authority in the work place, insufficient resources, time at work to implement changes in the practice. These results may be due to that majority of nurses were bedside nurses and didn't have authority to change the hospital routine, work overloads and multiple nursing roles on nurses due to decrease in nurses' number. The studied supervisors weren't motivated to change the practice and try new trends due to lack of managerial support to nurses to achieve more efforts in their work and lack of managerial awareness about importance of applying of evidence based practice, unavailability of national or international journals for nurses, neglection of pharmaceutical or equipment company representatives of giving the necessary information to nurses about the new issues in the field. 
This result came in accordance with Yadav \& Fealy (2012) ${ }^{(27),}$ who found that insufficient resources for implementing EBP was perceived as the greatest barrier to changing practice on the basis of best evidence, followed by a lack of authority to change.

Regarding nurses' knowledge about facilitation and support in changing practice (section VI), the present study shows that they expect that nursing colleagues, nurse managers, doctors with whom they work, practice managers will support them for changing practice if there are real opportunity to change the practice. These results may be probably due to that most of the studied nurses have the ability and the desire to change the practice if they get the necessary support and facilitation such as providing enough time and the appropriate number of nurses, getting enough authority and getting the needed experience from training, education and availability of experienced personnel in the work place. In this respect, Yadav \& Fealy (2012) ${ }^{(27)}$ agreed with the present study that practice development coordinators or clinical facilitators were the most supportive in assisting them to change their practice. But this was in contrast with the present study whereas nurse managers and nursing colleagues were perceived as the least supportive in changing practice.

In the same line, Olade (2003) ${ }^{(28)}$ in her study of attitudes and factors affecting research utilization that aimed to describe the attitude of nurses in rural settings toward nursing research and the relationship between selected variables and the nurses attitudes toward research. She reported that lack of consultative support and lack of encouragement from their organizational leaders, the lack of interest by the nurse administrators were some of the important barriers for utilization of scientific evidence for evidence-based practice stressed in the comments of those rural nurses who had the knowledge and interest in research but no encouragement from their nurse leaders.

Dogherty (2009) ${ }^{(29)}$, in her study on facilitation as a role and process in achieving evidence-based practice in nursing: A focused review of concept and meaning, facilitation is described as involving two major elements of „,supportingee and ,enablingee practitioners to improve practice through evidence implementation, that aimed to examine the current state of knowledge surrounding the concept of facilitation as a role 
and process in the implementation of evidence-based practice within the context of nursing reported that facilitation continues to be described as supporting and enabling practitioners to improve practice through evidence implementation. The main results were; facilitation is now being viewed as an individual role as well as a process involving individuals and groups, project management and leadership are important components, no specific approaches appear superior but tailoring facilitation to the local context is critical and there is growing emphasis on evaluation, particularly linking outcomes to nursing actions.

In this context, Brown (2009) ${ }^{(30)}$ in her study about nursing practice, knowledge, attitudes and perceived barriers to evidence-based practice at an academic medical center that aimed to describe nurses ${ }^{6}$ practices, knowledge, and attitudes related to evidence-based nursing, and the relation of perceived barriers to and facilitators of evidence based practice mentioned that respondents indicated that the availability of learning opportunities as (research discussion group, classes, and mentors to facilitate change), building culture as (mechanisms to implement change, involvement of staff nurses and environment that encourages thinking and rewards thinking), and availability and simplicity of evidence as (simple language, available sources and understandable concepts) were facilitator of EBP.

Regarding nurses self-assessment of skills (section V), the present study showed that the majority of nurses didn't have enough skills required for application of EBP represented in the following statements; finding research evidence, finding organizational information, using the library to locate information, using the internet to search for information, reviewing research evidence, reviewing organizational information, using research evidence to change practice, using organizational information to change practice. These results may be due to absence of technological facilities in the work place such as computers and libraries also insufficient technological training for nurses and low percentage of studied nurses who had quite skills don't have the capacity to read scientific books or search about new issues in psychiatric nursing. Also, they don't know scientific and professional databases and sites. Indeed, Yadav \& Fealy (2012) ${ }^{(27)}$ mentioned that over half of the respondents 
(51\%) rated themselves as competent or expert in using the Internet to search for information.

This result is in accordance with Dalheim, et al.(2012) ${ }^{(25)}$, who reported that most responding nurses rated their skills in evidence based practice as being beginner/novice. They explained the limited use of research based evidence by lack of competence in finding, assessing and understanding research.

Indeed, O'Donnell (2004) ${ }^{(31)}$ in her study an attitudes and knowledge of primary care professionals towards evidence-based practice: a postal survey that aimed to describe the attitudes, awareness and use of evidence across key professional groups working in primary care in Scotland reported that nurses have the necessary skills for reviewing and understanding researches and have more holistic view of research evidence.

Regarding attitude of nurses about EBP, the present study represented increased number of nurses having positive attitude immediately after implementation of the program. This result may be probably due to effective educational program sessions which gave the nurses the necessary and scientific knowledge about concept of evidence based practice and its importance in clinical practice, knowledge of the difference between the traditional practice and the evidence based practice.

The present study showed no relationship between difference in socio-demographic data of the studied nurses and attitude about EBP except the nursing expertise in which the nurses having experience less than 5 years were more positive regarding EBP. This result may be probably due to flexibility of the new generation of nurses to accept new concepts and their view that they still have enough time to change the practice to the best. Also, theses nurses are recently graduated and still have some knowledge from their educational courses that may contain knowledge about EBP but the old generations of nurses became more comfortable with the traditional care and may not have the capacity to deal with the new concepts and change.

Pryse (2012) ${ }^{(32)}$ in the study of using evidence based practice: the relationship between work environment, nursing leadership and nurses at the bedside that aimed to 
examine variables that describe the relationship among beliefs about EBP, the work environment and nursing leadership on the EBP implementation activities of the staff nurse, who reported that there is no relationship between the nurses' attitude and the education level and the length time of experience. On other hand, Pryse reported that there is a moderately significant positive correlation between nursing leadership and beliefs and attitudes about EBP in which the nurse manager's role in setting the milieu and fostering a positive attitude regarding beliefs and attitudes related to EBP.

Regarding relation between level of knowledge and attitude, the present study showed that there is a positive correlation between level of knowledge and attitude of the nurses regarding evidence based practice in which increase in nurses knowledge level led to improvement of their attitude about EBP. This result may be due to increased awareness of nurses about concept of EBP and its benefits in clinical practice for nurses, patients and hospitals and how it can increase the quality of nursing as a whole. In this respect, Hart (2008) ${ }^{(33)}$, in her study, effectiveness of a computer-based educational program on nurses' knowledge, attitude, and skill level related to evidencebased practice that aimed to conduct a baseline assessment of nurses' perceptions of knowledge, attitude, and skill level related to evidence-based practice and research utilization at Georgia. She reported that there are statistically significant differences in knowledge, attitude, and skill level, as well as beliefs about organizational readiness after nurses participated in the computer based education intervention.

In the same respect, Melnky, Fineout-Overholt \& Mays. (2008) ${ }^{(34)}$, in their study about the evidence-based practice beliefs and implementation scales: psychometric properties of two new instruments mentioned that the strength of beliefs in EBP was strongly associated with the frequency of implementing EBP and this relationship was strongest among participants who had prior training in EBP, training facilitated implementation of EBP. Similarly, the level of education was strongly associated with beliefs about EBP and implementation of EBP, suggesting that graduate education increases appreciation of the positive impact of EBP and instills a desire to use EBP to improve patient outcomes. Like educational level, the role was significantly associated with EBP beliefs and implementation with nurse educators and faculty having 
significantly stronger beliefs in EBP and implementing EBP significantly more frequently than did staff nurses.

From the point of view that using evidence based practice improve the patients care, Teresi, et al. (2013) ${ }^{(35)}$, in their study about comparative effectiveness of implementing evidence-based education and best practices in nursing homes: Effects on falls, qualityof-life and societal costs that aimed to conduct a comparative effectiveness research study to estimate the effects on falls, negative affect and behavior, and the associated societal costs of implementing evidence-based education and best practice programs in nursing homes found reduction of between 5 and 12 falls in a typical nursing home after implementation of the training program which led to cost saving. 


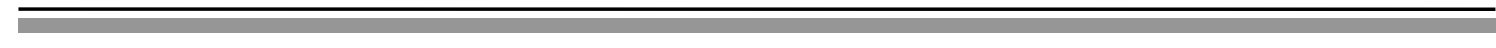




\section{Conclusion}

According to the findings of the present study, it can be concluded that building a culture in which research is valued and EBP becomes the norm among nurses and nurse leaders is essential to the progression of nursing practice. Evidence based practice is greatly important for nurse and patient and overall nursing profession. Nurses are able to work with new trends if they received the necessary information, training and support for this. Diverse and effective methods are essential in educating and engaging nurses in EBP. The findings point to the need for research-based information, exposure to professional journals and, in particular, organizational support for evidence-based nursing practice.

\section{Recommendation :}

- Generalize the application of the educational program for all psychiatric nurses to provide a better understanding about concept of psychiatric evidence based nursing practice.

- Continuous In-service training programs need to be implemented for nurses to provide necessary skills for application of EBP in clinical practice area.

- Educate the nurses the principles of scientific research.

- Provide ways of accessing information to nursing staff as internet unit, library books and digital library.

- Provide encouragement and rewards for nurses who attend committees and workshops.

- Provide reinforcement as financial rewards for nurses who do researches in psychiatric nursing issues.

- Provide plans for continuous updating of the available scientific content to renew the nurses' information and skills.

- Annual research plan should be formulated to ensure continuity of research process. 
27 


\section{References}

1. Fontaine $L$ K. Mental Health Nursing. $6^{\text {th }}$ ed. USA: Pearson Education. 2009;31-32

2. Cleary-Holdforth J, Leufer T. Essential elements in developing evidence-based practice. Nursing Standard, 2008; 23(2): 42-46.

3. Hasnain-Wynia $\boldsymbol{R}$. Is evidence-based medicine patient-centered, and is patient-centered care evidence-based?. Health Services Research, 2006; 41: 1-8.

4. Ballard K. Issues and Trends in Psychiatric Mental Health Nursing. Jones and Bartlett publishers, 21-37. Retrieved March 20 , 2014, from ww.jblearning.com/.../44344_CH02_021_038.pdf

5. Gibbs L, Gambrill E. Evidence-based practice: counterarguments to objections. Sage journals, 2002; 12 (3): 452-76

6. Profetto-McGrath J. Critical Thinking and Evidence Based Practice. Journal of Professional Nursing, 2005; 21(6): 364-71.

7. Cleary-Holdforth J, Leufer T. Evidence-based practice: sowing the seeds for success. Nurse Education in Practice Journal, 2009; 9: 285-87

8. Alzayyat A. Barriers to evidence-based practice utilization in psychiatric/mental health nursing. Issues in Mental Health Nursing Journal, 2014; 35(2): 134-43

9. Rickbeil P, Simones $\boldsymbol{J}$. Overcoming barriers to implementing evidence-based practice: a collaboration between academics and practice. Official Journal of the National Nursing Staff Development Organization, 2012; 28(2): 53-56.

10. Hussein A, Hussein $\boldsymbol{R} \boldsymbol{G}$. The attitudes and barriers towards evidence-based practice among nursing educators. Journal of American Science, 2013; 9(12): 609-18

11. Fehr S. Examining the relationship between nursing informatics competency and evidencebased practice competency among acute care nurses. ProQuest LLC, 2014; 1-15

12. Stuart $\boldsymbol{G W}$. Evidence-based psychiatric nursing practice: rhetoric or reality. Journal of The American Psychiatric Nurses Association, 2001; 7(4): 103-14.

13. Schalock R, Verdugo M, Gomez L. Evidence-based practices in the field of intellectual and developmental disabilities: an international consensus approach. Evaluation and Program Planning Journal, 2011; 34: 273-82 
14. Tucker S, Brust $S$. Establishing an empirically based psychiatric nursing practice in a rapidly changing health care environment. Journal of the American Psychiatric Nurses Association, 2000; 6(4): 112-18.

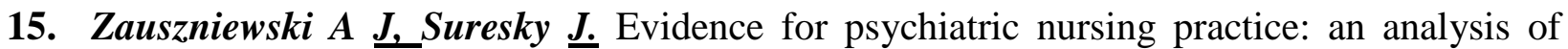
three years of published research. The Online Journal of Issues In Nursing, 2004; 9(1)

16. Aarons $G$. Mental health provider attitudes toward adoption of evidence-based practice: the evidence based practice attitude scale. Mental Health Services Research Journal, 2004; 6: 61-72.

17. Gerrish K., Ashworth P., Lacey A. Factors influencing the development of evidence-based practice: a research tool. Journal of Advanced Nursing, 2007; 57: 328-38

18. Boyd M. Psychiatric Nursing Contemporary Practice. $5^{\text {th }}$ ed. Philadelphia: Lippincott. 2012; 3.

19. Brown S. Evidence Based Nursing: The Research Practice Connection. $3^{\text {rd }}$ ed. USA: Jones \& Bartlett. 2014; 5-13 2

20. Boyd M. Psychiatric Nursing Contemporary Practice. $5^{\text {th }}$ ed. Philadelphia: Lippincott. 2012; 3.

21. Stuart G. Principles and Practice of Psychiatric Nursing. $1^{\text {0th }}$ ed. China: Elsevier. 2013; 5864.53

22. Beyea S, Slattery $M$. Evidence-based practice in nursing a guide to successful implementation. Health Care Production Company, Inc. 2006; 1: 11.

23. Fortinash K. Psychiatric Nursing Care Plans. $5^{\text {th }}$ ed. USA: Mosby, 2007; 139- 84

24. Neilson $\boldsymbol{L}$. Evidence-based best practice interventions for the treatment of schizophrenia/psychotic disorders: annotated information package. Christchurch School of Medicine and Health Sciences Christchurch, New Zealand, 2007; 1-31. Reteived April, 2014, from ww.nmdhb.govt.nz/.../New\%20Website/.

25. Dalheim A, Harthug S, Nilsen R, Nortved M. factors influencing the development of evidence-based practice among nurses: a self-report survey. BMC Health Services Research Journal. 2012;12:1-10

26. Olade $\boldsymbol{R} \boldsymbol{A}$. Strategic collaborative model for evidence-based nursing practice. Worldviews on Evidence-Based Nursing Jounal, 2004; 1: 60-68 
27. Yadav B L, Fealy $\boldsymbol{G} \boldsymbol{M}$. Irish psychiatric nurses' self-reported barriers, facilitators and skills for developing evidence-based practice. Journal of Psychiatric and Mental Health Nursing, 2012; 19: 116-22

28. Olade $\boldsymbol{R}$ A. Attitudes and Factors Affecting Research Utilization. Nursing Forum Jounal, $2003 ; 38(4): 5-15$

29. Dogherty $\boldsymbol{E} \boldsymbol{J}$. Facilitation as A Role And Process In Achieving Evidence-Based Practice In Nursing: A Focused Review Of Concept and Meaning. Queen's University Kingston, Ontario, Canada, 2009; 20-55

30. Brown $\boldsymbol{C} \boldsymbol{E}$. Nursing practice, knowledge, attitudes and perceived barriers to evidencebased practice at an academic medical center. Advanced Nursing Journal, 2009; 65(2):371381.

31. O'Donnell $\boldsymbol{C} \boldsymbol{A}$. Attitudes and knowledge of primary care professionals towards evidencebased practice: a postal survey. Journal of Evaluation in Clinical Practice, 2004; 10(2):197205

32. Pryse Y M. Using Evidence Based Practice: The Relationship Between Work Environment, Nursing Leadership and Nurses at The Bedside. ProQuest LLC, 2012; 101-18

33. Hart P, Eaton L, Buckner M, Morrow B, Barrett D, Danielle D, Hooks D, Sharrer R. effectiveness of a computer-based educational program on nurses' knowledge, attitude, and skill level related to evidence-based practice. Worldviews on Evidence-Based Nursing Journal, 2008; 5(2): 75-84

34. Melnyk B M, Fineout-Overholt E, Mays M Z. The evidence-based practice beliefs and implementation scales: psychometric properties of two new instruments. Worldviews on Evidence-Based Nursing Journal, 2008:208-16

35. Teresi J A, Ramirez $M$, Remler D, Ellis J, Boratgis $G$, Silver S, Lindsey M, Kong J,

Eimicke J P, Dichter E. Comparative effectiveness of implementing evidence-based education and best practices in nursing homes: effects on falls, quality-of-life and societal costs. International Journal of Nursing Studies 
6- Schirmer J. ,Mauksch L .,Lang F.,Marvel K., Zoppi ,Epstein R., Brock D\& Pryzbylski M: Assessing Communication Competence: A Review of Current Tools, Medical Student Education and Family Medicine.2005; 37(3).184-192.

7- Cook R. t., Render m \& Awoods D.P: Gaps in the continuity of Care and progress on patient safety , British Medical Journal , (2000) ; 320: 791- 794.

8- Shives L. R: Basic Concepts of Psychiatric Mental Health Nursings,5 thed, Com ., Philadelphia , Lippincott, 2002; 41-49 .

9-Nikendei C., Bosse H.M., Hoffmann K., Moltner A., Hancke R \& Conrad C., : Outcome of Parent-Physician Communication Skills Training for Pediatric Residents. Patient Education and Counseling. Iranin Journal of Nursing and Midwifery, 2011;82(1):94-9.

10-Chiovitti R.F: Nurses' Meaning of Caring With Patients in Acute Psychiatric Hospital Settings: A Grounded Theory Study. International Journal of Nursing Studies. 2008;45(2):20323.

11-Bylund C.L., Brown R.F., Ciccone B.L., Levin T.T., Gueguen J.A., Hill C \& Kissane D.W: Training Faculty to Facilitate Communication Skills Training: Development and Evaluation of A workshop, Patient Education and Counseling. Iranin Journal of Nursing and Midwifery, 2008;70(3):430-6.

12-Shattell M.M., McAllister S., Hogan B \& Thomas S.P: "She Took The Time to Make Sure She Understood": Mental Health Patients Experiences of Being Understood. Journal of Psychiatry Nurses , 2006;20(5):234-41.

13-Jones A: Nurse Talking to Patient: Exploring Conversation Analysis as Amean of Researching Nurse - Patient Communication, International Journal of Nursing Studies .2003; 40 (6) :609-18.

14-Oandasan I .,Baker G.R \& Barker K: Teamwork in Healthcare: Promoting Effective Teamwork in Healthcare in Canada Canadian Health Research Foundation June 2006; 85-90.

15-Mohr W: Psychiatric Mental Health Nursing $7^{\text {th }}$ ed com ., . Philadelphia Lippincott.2009; 188-189.

16-CeccioT .F. A\& ceccio C .M: Effective communication in Nursing : Theory and Practice Journal of Advanced Nursing . 1999; 29-1921 -1426.

17-Worren B T:Cultural Competence Abest Practice Process for Psychiatric Mmental Health Nursing . Journal of the American Psychiatric Nurses Association ,2000; 112: 35

18-Fakhoury W.K\& Wright D: Communication and Information Needs of A random Sample of Community Psychiatric Nurses in the United Kingdom. Journal of Advanced Nursing. 2000;32(4):871-80. 
19-Edwards N., Peterson W.E \& Davies B.L: Evaluation of a Multiple Component Intervention to Support the Implementation of a 'Therapeutic Relationships' Best Practice Guideline on Nurses' Communication Skills. Patient Education and Counseling. Iranin Journal of Nursing and Midwifery, 2006;63(1-2):3-11.

20-Heaven C., Clegg J\& Maguire P: Transfer of Communication Skills Training from Workshop to Workplace: the Impact of Clinical Supervision. Patient Education and Counseling. Iranin Journal of Nursing and Midwifery, 2006;60(3):313-25.

21-Fetzer B G: Conference on Physician- Patient Communication in Medical Education: Communication checklist: The Kalamazoo Consensus Statement Academic Medicine 2001; 76 (4): $-390-393$.

22- Sharac, J., McCrone, P., Sabes-Figuera, R., Csipke, E., Wood, A., \&Wykes, T. Nurse and Patient Activities and Interaction on Psychiatric In Patients Wards: a Literature Review. International Journal of Nursing Studies, 47(7), 2010; 909-917.

23-Bowers, L., Brennan, G., Winship, G., \&Theodoridou, C. How Expert Nurses Communicate with Acutely Psychotic Patients. Mental Health Practice, 2012 13(7), 24-26.

24-Ward, L. Ready, Aim Fire! Mental Health Nurses under Siege in Acute Inpatient Facilities. Issues in Mental Health Nursing, 2013 34(4), 281 - 87.

25-Erchul, W.P\&Martens,K. Caplan's Preventive Model. School Consultation; Conceptual and Empirical Bases of Practice. $3^{\text {rd }}$ Ed. Springersny.2014 Chapter 5. 33; 90.

26-Rose L. Moss. Communication Skills of Novice Psychiatric Nurses with Aggressive Psychiatric Patients (Doctor Thesis)College of Health Sciences Walden University; 2015.

27-Anderson, A., \& West, S. G. Violence against mental health professionals: When the treater becomes the victim. Innovation in Clinical Neuroscience, 2013 8(3), 34-39. Retrieved from http://www.ncbi.nlm.nih.gov/pmc/articles/PMC3074201

28- Kelly, J. An overview of conflict. Dimensions of Critical Care Nursing, 2009 25(1), 22-28.

29-Kwadwo Ameyaw Korsah.Nurses' stories about their interactions with patients at the Holy Family Hospital, Techiman, Ghana Open Journal of Nursing, 2011, 1, 1-9.

30- vahidZamanzadeh et al. Factors Influencing Communication between the Patients and their Nurses Indian. Journal of Palliative Care, 2014 Jan-Apr; 20(1): 12-20.

31-Neumann et al. poor nurse patient communication in mental health setting nursing essay. http://www.ukessays.com/essays/nursing/.php\#ixzz3IGAfvHxu Copyright @ 2012.

32 -Mavundia,T.R. Professional Nurses Perception of Nursing Mentally Ill People in a General Hospital Setting. Journal of Advanced nursing; 2009,32(6)1569-1578, Available from http:// oweb.ebscohost. Com. utlink. At. Ac. Za/ ehost/ results vid pdf(Accessed10 Jun2009).

33-Vgthilinyum, B. Anxiety Disorder in Pregnancy and the Postnatal Period. Continuing Medical Education. 2009; 27(10); 450-452

34-Hamdan-Mansour, A. M., \&Wardam, L. A. Attitudes of Jordanian Mental Health Nurses Toward Mental Illness and Patients with Mental Illness. Issues in Mental Health Nursing, 2011; 30(11), 705-711.

35-Jacob, J. D., \& Holmes, D: Working under Threat: Fear and Nurse-Patient Interactions in a Forensic Psychiatric Setting. Journal of Forensic Nursing, 2013; 7(2), 68-77.

36-Hem \&Heggen. Poor Nurse Patient Communication in Mental Health Setting Available-at: 
